\title{
Evaluation of complete edentulous patient's satisfaction with the new dentures
}

\author{
Evaluarea satisfacției pacienților edentați total în noua protezare \\ Ana Maria Cristina ȚÂNCU ${ }^{1}$, Mihaela PANTEA ${ }^{2}$, Alexandra TOTAN ${ }^{3}$, Elena PREOTEASA ${ }^{1}$, \\ Marina MELEȘCANU IMRE ${ }^{1}$ \\ ${ }^{1}$ Disciplina Protezare Totală, Facultatea de Medicină Dentară, \\ Universitatea de Medicină şi Farmacie „Carol Davila“, București, România \\ ${ }^{2}$ Disciplina Protetică Dentară Fixă și Ocluzologie, Facultatea de Medicină Dentară, \\ Universitatea de Medicină şi Farmacie „Carol Davila“, București, România \\ ${ }^{3}$ Disciplina Biochimie, Facultatea de Medicină Dentară, \\ Universitatea de Medicină şi Farmacie „Carol Davila“, București, România
}

\begin{abstract}
REZUMAT
Obiectiv. Evaluarea comparativă a satisfacției pacienților edentați total protezați la o nouă protezare, din punctul de vedere al echilibrului, funcționalității și aspectelor estetice.

Material și metodă. Studiul comparativ a fost realizat pe baza unui chestionar cu 22 de intrebări, aplicat unui lot de 30 de pacienți edentați total bimaxilar protezați, ce s-au prezentat pentru o nouă protezare. Studiul a fost realizat pe o perioadă de 3 ani (2012-2014), alegându-se un lot de 10 pacienți din fiecare an. Răspunsurile au fost centralizate și prelucrate statistic.

Rezultate și discuții. În toți cei 3 ani luați în studiu, așteptările marii majorități a pacienților din punctul de vedere al funcționalității și criteriilor estetice (mărime, formă și culoare a dinților, aranjament, curbură vestibulară, grad de vizibilitate) au fost îndeplinite după aplicarea noilor proteze, gradul de satisfacție fiind superior primei protezări. Au existat totuși un număr foarte mic de pacienți (1-2), în fiecare dintre cei 3 ani, care nu au fost în totalitate satisfăcuți de echilibrul noilor proteze (în special mandibulare) și de masticația cu acestea. În urma analizei statistice, s-a constatat că bărbații sunt mai nesatisfăcuți, de regulă, de funcția masticatorie asigurată de proteze, iar femeile - de funcția estetică. Funcția fonatorie s-a dovedit a fi satisfăcută în egală măsură la ambele sexe.

Concluzii. Gradul de satisfacție a pacienților după inserarea protezelor noi a fost mai mare comparativ cu vechea protezare, atât din punct de vedere funcțional, cât și din punct de vedere estetic. Satisfacția pacienților intr-o nouă protezare totală, multifactorială, este un determinant puternic al succesului și unul dintre principalele obiective ale acestui tip de tratament.
\end{abstract}

Cuvinte cheie: protezarea edentației totale, satisfacția pacientului

\section{ABSTRACT}

Objective. The comparative evaluation between the new and old complete dentures regarding equilibrium, functionality and aesthetic criteria.

Material and method. A comparative study, based on a 22 questions enquiry was performed and applied to 30 complete bimaxilary edentulous patients, who came for a new prosthetic treatment. The study was per- 
formed in a 3 years period of time (2012-2014) and 10 patients were chosen from every year. The answers were colected and a statistical analysis was performed.

Results and discussions. In each year of the 3 studied, almost all patient's expectations, regarding functionality and aesthetic criteria (size, form and colour of teeth, vestibular curvature, teeth visibility), with the new dentures, were fulfilled, with an improvement of the satisfaction's degree, related to the previous dentures. After the statistical analysis, men were more unsatisfied by the masticatory function offered by the new dentures and the women by the aesthetic criteria, both being satisfied by the phonation.

Conclusions. The satisfaction degree with the new dentures was better related to the old ones, functionally and aesthetically. Patients satisfaction in a new complete denture treatment multifactorial is an important determinant of the success and objective of this type of treatment.

Keywords: new complete dentures, patient's satisfaction

\section{INTRODUCERE}

Creșterea calității vieții, alături de scăderea ratei mortalității, a condus la creșterea numărului de persoane în vârstă la nivel global (1). În ciuda descreșterii globale a ponderii edentației totale, cu un număr mare de persoane ce ajung la o vârstă înaintată, numărul pacienților edentați total continuă să fie mare $(3,4)$. În contextul presiunii demografice realizate de segmentul populațional de peste 65 de ani, este evident că ponderea problemelor de sănătate specifice acestei categorii de vârstă crește, reprezentând o adevărată provocare pentru lumea medicală $(2,9)$.

Deoarece edentația totală este o boală cronică, îmbunătățirea funcționalității este mai importantă decât vindecarea, de aceea percepția pacientului și satisfacția privind aceste aspecte sunt cele mai importante (5). Alte studii publicate susțin această teorie, arătând că satisfacția acestuia, bazată pe evaluarea funcțională, diferențiază tratamentele (6). Percepția pacientului despre experiența subiectivă în protezarea totală este importantă pentru medicii stomatologi și pentru motivarea purtătorilor de proteze totale (7).

Diferitele variabile social-demografice, ca vârsta, sexul și bolile generale, pot afecta satisfacția cu protezele totale. Diferite studii au eșuat în a dovedi corelații semnificative fie între satisfacția pacienților cu protezele și calitatea acestora, fie între satisfacția cu protezele și calitatea țesuturilor de suport $(1,8)$. Pacienții evaluează protezele dentare din punctul de vedere al satisfacției lor, care este diferit de cel al medicului, cuprinzând abilitatea de a folosi proteza pentru masticație și fonație, considerațiile proprii asupra esteticii, factorii psihologici și atitudinea pacientului influențând capacitatea de a se adapta, a accepta și chiar a manipula protezele. Astfel, satisfacția pacientului reprezintă un determinant puternic al succesului atins în protezarea totală. Satisfacția pacientului privind protezarea totală este multifactorială, fiind rezul- tanta interacțiunii a diferiți factori psihologici, biologici, anatomici și de construcție.

Este general acceptat faptul că există diferențe de sex în capacitatea pacienților de adaptare la protezele totale. Numeroase studii analizează satisfacția în protezarea totală, raportată la sexul pacientului. Totuși, în literatura de specialitate, un număr mic de studii evaluează satisfacția pacienților edentați total protezați după aplicarea unor noi proteze, de aceea, studiul nostru își propune analiza acesteia, evaluând funcționalitatea și estetica noilor proteze totale.

\section{MATERIAL ŞI METODĂ}

Studiul s-a realizat în cadrul Facultății de Medicină Dentară a UMF „Carol Davila“ din București, la Disciplina de Protezare Totală, pe un lot de 30 de pacienți care au fost în tratament în perioada 20122014, din fiecare an fiind selectați 10 pa-cienți. Participanții la studiu au fost aleși prin intermediul unei scheme de eșantionare din punct de vedere temporal pe o perioadă de 3 ani. S-a selectat un număr de 30 de pacienți edentați total protezați care s-au prezentat în clinica noastră pentru refacerea funcției masticatorii, estetice și a echilibrului protezei, aceștia fiind nemulțumiți de vechile proteze. Criteriul de includere a fost edentația totală bimaxilară protezată și cu vechime mai mare de 5 ani. Marea majoritate a pacien-ților prezentau afecțiuni generale. De asemenea, pacienții au semnat un consimțământ informat în care și-au dat acordul de includere în lotul de studiu. Înregistrarea s-a realizat cu ajutorul chestionarelor de tip calitativ în care $\mathrm{s}$-au preferat răspunsurile deschise ale respondenților. Chestionarul a cuprins o serie 22 de întrebări ample din care s-au selectat răspunsurile ce ne ofereau date privind satisfacția.

Criteriile privind satisfacția pacientului au fost legate de aspecte precum menținere și stabilitate, masticație, fonație, precum și de aspecte estetice 
- culoarea, forma și mărimea dinților, vizibilitatea acestora în surâs și zâmbet, curbura vestibulară, aranjamentul dinților.

\section{REZULTATE ŞI DISCUȚII}

Răspunsurile din chestionar au fost în registrate în trei tabele, unul pentru fiecare an. Eșantionul a fost format dintr-un număr de 19 bărbați și 11 femei cu vârste cuprinse între 40 și 90 de ani. Grupa de vârstă predominantă a fost de 70-80 de ani.

În ceea ce privește nivelul satisfacției, s-au realizat grafice pe fiecare an în care s-au înregistrat criteriile stabilite prin comparația protezelor vechi cu cele noi. Nivelul comparativ al satisfacției a fost înregistrat în anul 2012, 2013, respectiv 2014, realizându-se și o înregistrare globală.

Satisfacție 2012

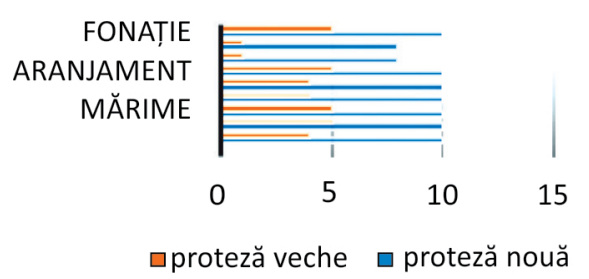

FIGURA 1. Evaluarea comparativă a nivelului de satisfacție dintre proteza veche şi cea nouă în anul 2012

În anul 2012, principalele doleanțe ale pacienților în vederea unei noi protezări au fost legate de funcția masticatorie, precum și de menținerea și stabilitatea protezei pe câmpul protetic, acestea fiind reclamate în principal de sexul masculin. Femeile au fost în schimb mai nemulțumite în privința funcției estetice și, mai exact, a curburii vestibulare, a vizibilității, precum și a culorii dinților artificiali. Fonația și celelalte aspecte estetice, aranjamentul, mărimea și forma s-au arătat a fi cel mai puțin deranjante pentru pacienți.

În urma realizării noilor proteze, așteptările pacienților au fost îndeplinite, cu excepția a 2 persoane, care au declarat că nu sunt mulțumite pe deplin de masticația pe care o pot efectua cu noile proteze și de menținerea și stabilitatea protezei.

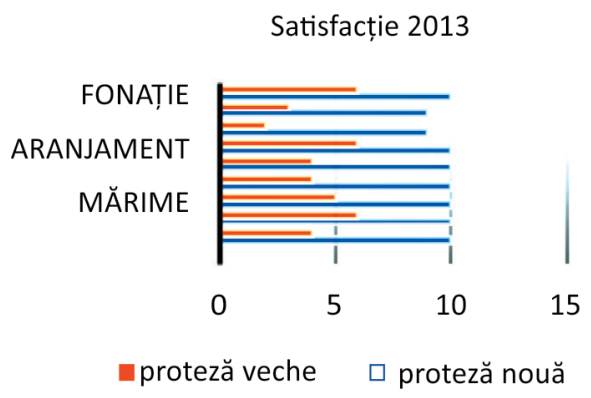

FIGURA 2. Evaluarea comparativă a nivelului de satisfacție dintre proteza veche şi cea nouă în anul 2013
Nivelul satisfacției în anul 2013 a fost asemănător anului 2012, întrucât aceleași probleme au fost amintite de către pacienți și, de asemenea, după realizarea noilor proteze, pacienții s-au arătat nemulțumiți de aceleași aspecte, și anume cele legate de funcția masticatorie și, într-un număr mai mic, cei cu acuze referitoare la menținerea și stabilitatea protezelor.

Puțini pacienți au declarat nemulțumirea față de fonație, aranjament și forma dinților, dar în schimb au mai fost sesizări și asupra curburii vestibulare, a vizibilității dinților și a culorii.

Gradul de satisfacție asupra funcției fonatorii și aspectelor estetice, aranjament, curbură vestibulară, vizibilitate, mărime, formă și culoare a dinților în noua protezare a fost la nivel maxim la toți pacienții chestionați.

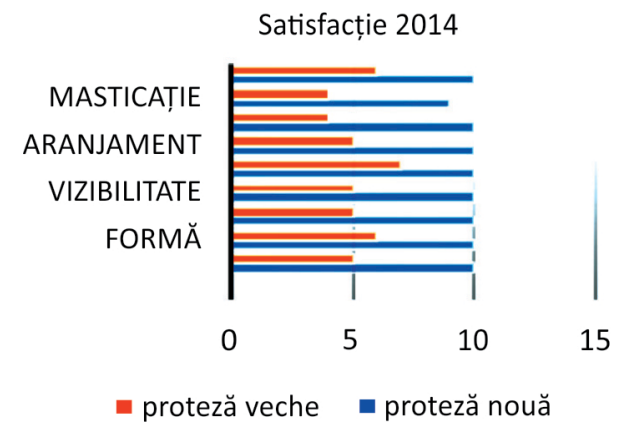

FIGURA 3. Evaluarea comparativă a nivelului de satisfacție dintre proteza veche şi cea nouă în anul 2014

Anul 2014 s-a dovedit a fi un an în care pacienții au fost mai mulțumiți în privința aspectelor urmărite. Ca și în ceilalți ani, problemele principale pentru care pacienții s-au prezentat pentru o nouă protezare au fost legate de menținere, stabilitate și de funcția masticatorie. Fiind un an în care au fost chestionate mai multe femei decât bărbați, s-a constatat că nemulțumirile principale au fost de ordin estetic, pacienții având doleanțe privind aranjamentul, vizibilitatea, mărimea și culoarea dinților.

În urma chestionării, după aplicarea protezelor noi, pacienții au răspuns că sunt mulțumiți în totalitate de refacerea funcției fonatorie și a celei estetice. Un singur pacient a apreciat că funcția masticatorie nu i-a fost îndeplinită conform așteptărilor sale.

În urma evaluării comparative a nivelului de satisfacție dintre proteza veche și cea nouă, s-a constat că principalele probleme pentru care pacienții s-au prezentat au fost refacerea funcției masticatorii și echilibrul protezelor (menținere și stabilitate). Pacienții s-au arătat mai puțin interesați de culoarea dinților, vizibilitate și curbura vestibulară. Forma dinților și fonația au fost 
semnalate de către pacient într-o măsură foarte mică, ele nereprezentând pentru majoritatea o nemulțumire care să îi determine să solicite realizarea unor proteze noi.

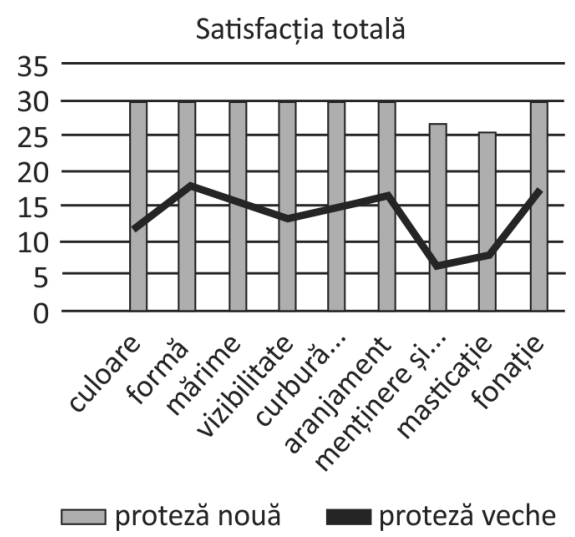

FIGURA 4. Evaluarea comparativă a nivelului de satisfacție dintre proteza veche şi cea nouă în toți anii

Noua protezare a reușit să sporească gradul de satisfacție a pacienților, aceștia fiind mulțumiți în totalitate de aspectele ce privesc funcția estetică, precum și funcția fonatorie. În ceea ce privește echilibrul noilor proteze (menținerea, stabilitatea) și masticația, chiar și după realizarea noilor proteze au existat pacienți care au declarat că nu sunt satisfăcuți.

Întrucât eșantionul a aparținut predominant genului masculin, în urma înregistrării răspunsurilor, s-a constatat că bărbații sunt mai nesatisfăcuți de regulă de funcția masticatorie, iar femeile își reprezintă nemulțumirile mai des asupra funcției estetice. Funcția fonatorie s-a dovedit a fi satisfăcută în egală măsură la ambele sexe.

Rezultatele pe care le-am obținut au arătat niveluri mai ridicate ale satisfacției după tratament. Aceste niveluri de satisfacție înalte sunt congruente cu alte studii în care pacienții se declară, de asemenea, mai mulțumiți după tratament decât înainte.

Studiul prezent a efectuat o analiză atât a gradului de satisfacție pe care pacienții îl aveau la proteza totală veche, cât și a gradului de satisfacție obținut în urma unei noi protezări. Conform așteptărilor, gradul de satisfacție după inserarea protezei noi a fost mai mare decât înaintea tratamentului, atât din punct de vedere funcțional, cât și din punct de vedere estetic. Principalele nemulțumiri din lotul studiat au fost preponderent de ordin funcțional, primând echilibrul (menținerea și stabilitatea) și masticația. De asemenea, tot referitor la echilibru și masticație, la finele tratamentului, nu a fost atinsă satisfacția deplină în cadrul tuturor pacienților. În ceea ce privește doleanțele pacienților față de aspectul estetic, aceștia s-au arătat mai mulțumiți și înaintea începerii tratamentului, dar și de caracteristicile estetice obținute după inserarea protezelor noi.

Conform studiului lui Seenivasan M și colab., din iunie 2019 (1), satisfacția mai mare după prima protezare totală a fost înregistrată între persoanele de sex feminin din lotul de studiu. Pratap Singh B și colab. (7), în 2012, au concluzionat, după un studiu efectuat pe un lot de 100 pacienți edentați total aflați la prima protezare totală, că satisfacția în protezare a fost mai mare în cazul pacienților de sex masculin, comparativ cu reprezentantele sexului feminin. Taylor și Doku (12) au investigat un număr de 29 de bărbați și 30 de femei, purtători de proteze totale, cu vârste între 52 și 92 de ani, și au constatat că bărbații sunt mai satisfăcuți decât femeile. Awad și Feine (13) și Baer și colab. (14) au concluzionat că satisfacția este dependentă de gen.

Din aceste studii, putem concluziona că satisfacția mai mare după prima protezare se înregistrează în rândul persoanelor de sex masculin comparativ cu cele de sex feminin din lotul de studiu. Doleanțele privind aspectele de ordin funcțional sunt întâlnite mai frecvent la genul masculin, în schimb, nemulțumirile privind aspectele de ordin estetic sunt întâlnite în cadrul persoanelor de gen feminin.

O altă remarcă ar fi că gradul de satisfacție obținut în urma tratamentului este întotdeauna mai mare decât înaintea începerii tratamentului, rezultatele fiind, în majoritatea cazurilor, conform așteptărilor, excepție făcând masticația și echilibrul, de care unii pacienți s-au declarat nemulțumiți pe deplin după noua protezare.

În ceea ce privește gradul de satisfacție a pacienților în protezarea totală, pentru pacienții aflați la a doua protezare, comparativ cu cei aflați la prima protezare, un studiu publicat în anul 2009 de Bellini și colab. (10) a fost realizat pe 64 de subiecți care s-au prezentat pentru refacerea funcționalității și esteticii printr-o nouă protezare la Universitatea Vale do Paraiba și la Universitatea Taubate. În acest eșantion, 59\% au fost femei, iar vârsta medie a fost de 60 de ani, pacienții având vârsta cuprinsă între 37 și 87 de ani. Criteriul de includere în studiu a fost ca pacienții să fie edentați total și să aibă proteză veche de mai mult de 5 ani. În acest studiu, principalele nemulțumiri au fost de ordin estetic, înregistrând cel mai mic punctaj, cu valori între 4 și 10 înainte de tratament și între 8 și 10 după inserarea protezei noi. Protezarea nouă în viața unui pacient protezat anterior s-a dovedit a-i crește gradul de satisfacție, precum și calitatea vieții. 
Rezultatele studiului nostru arată clar că gradul de satisfacție după inserarea protezelor noi a fost mai mare decât înaintea tratamentului, în ceea ce privește îmbunătățirea echilibrului, a funcționalității și a esteticii noilor proteze.

Doleanțele privind aspectele de ordin funcțional sunt întâlnite mai frecvent la genul masculin, în schimb, nemulțumirile privind aspectele de ordin estetic sunt întâlnite în cadrul persoanelor de gen feminin.

\section{CONCLUZII}

Protezarea nouă în viața unui pacient edentat total protezat anterior s-a dovedit a-i crește gradul de satisfacție, precum și calitatea vieții, atât din punct de vedere funcțional, cât și din punct de vedere estetic. Satisfacția pacienților într-o nouă protezare totală, multifactorială, este un determinant puternic al succesului și unul dintre principalele obiective ale acestui tip de tratament, ce ar trebui atins de către toți practicienii.

Conflict of interest: none declared Financial support: none declared

\section{BIBLIOGRAFIE}

1. Seenivasan MK, Banu F, Inbarajan A, Natarajan P, Natarajan S, Anand Kumar V. The Effect of Complete Dentures on the Quality of Life of Edentulous Patients in the South Indian Population Based on Gender and Systemic Disease. Cureus. 2019 Jun 17;11(6):e4916.

2. Pantea M, Tancu AMC, Meleșcanu-Imre M, Ionescu E. Aspecte ale calității vieții persoanelor vârstnice în raport cu sănătatea orală. Revista Română de Stomatologie. 2014; LX (4): 245-250.

3. He W, Sengupta M, Velkoff VA, De Barros KA: $65+$ in the United States, Current Population Reports. 2005, 2:23-209.

4. Slade GD, Spencer AJ: Development and evaluation of the oral health impact profile Community Dent Health. 1994, 11:3-1.

5. Silverman W.A. Doing more good than harm. Ann N Y Acad Sci 1993;703:5-11.

6. Feine JS, de Grandmont $P$, Boudrias $P$, Brien N, LaMarche C, Taché R, Lund JP.
Within-subject comparisons of implantsupported mandibular prostheses: choice of prosthesis. J Dent Res 1994;73:1105-1111.

7. Singh A, Pradhan KN, Arvind Tripathi A, Tua R, Tripathi S. Effect of sociodemographic variables on complete denture satisfaction. J AProsthodont. 2012 Feb;4(1):43-51.

8. Langer A, Michman J, Seifert I. Factors influencing satisfaction with complete dentures in geriatric patients. Complete Denture vol. 11, no. 6, pp.1019-1031.

9. Emami E, Freitas de Souza R, Kabawat M, Jocelyne S, Feine JS. The Impact of Edentulism on Oral and General Health. International Journal of Dentistry, Volume 2013, Article ID 498305, p.3.

10. Douglass CW, Shih A, Ostry L. Will there be a need for complete dentures in the United States in 2020?. Journal of Prosthetic Dentistry, vol. 87 , no. 1, pp. 5-8, 2002, vol. 53, pp. 327-334, 2003.
11. Bellini D, Dos Santos MBF, De Paula Prisco V, Da Cunha, Marchini L. Patients expectations and satisfaction of complete denture therapy and correlation with locus of control. Journal of Oral Rehabilitation 2009 pp.36; 682-68.

12. Taylor RG, Doku HC. Dental survey of healthy older persons. J Am Dent Assoc 1963; 67:63-70.

13. Awad MA, Feine JS. Measuring patient satisfaction with mandibular prostheses Community Dent Oral Epidemiol 1998; 26:400-5.

14. Baer ML, Elias SA, Reynolds MA. The use of psychological measures in predicting patient satisfaction with complete dentures. Int J Prosthodont 1992; 5:221-6. 